Ciência Florestal, Santa Maria, v. 12, n. 2, p. 27-39

ISSN 0103-9954

\title{
FLORESTA OMBRÓFILA DENSA ALTOMONTANA: ASPECTOS FLORÍSTICOS E ESTRUTURAIS DE DIFERENTES TRECHOS NA SERRA DO MAR, PR
}

\author{
UPPER MONTANE RAIN FOREST: FLORISTIC ASPECTS ABOUT THE AND STRUCTURE OF \\ DIFFERENT STANDS, IN SERRA DO MAR, PR
}

Alexandre Koehler ${ }^{1}$ Franklin Galvão ${ }^{2}$ Solon Jonas Longhi ${ }^{3}$

\section{RESUMO}

Foram avaliadas a florística e a estrutura da Floresta Ombrófila Densa Altomontana, em cinco diferentes montanhas, ao longo da Serra do Mar, PR. Trechos primários, sempre acima dos $1.250 \mathrm{~m}$, foram mensurados, com dez parcelas retangulares $(5 \times 10 \mathrm{~m})$, em cada local. Foram registradas 55 espécies arbóreas, 36 gêneros e 24 famílias. Incluíndo dados de outros autores, foi possível revelar que Ilex microdonta é a espécie mais importante, seguida por Drimys brasiliensis, Ocotea catharinensis, Blepharocalyx salicifolius e Gordonia fruticosa. Constatou-se a elevada densidade arbórea, até 4.490 árvores por hectare (PAP $>10 \mathrm{~cm}$ ), formando um estrato único, com altura média de $4 \mathrm{~m}$. Na análise de agrupamentos, os melhores resultados foram obtidos adotando-se a variável Valor de Importância. A menor similaridade estrutural foi registrada entre os trechos dos morros Ara çatuba (1.610 m s.n.m.) e Vigia (1.280 m s.n.m.), indicando que o fator altitude exerce grande influência nesse aspecto. Contudo, verificou-se, com base no índice de Jaccard, que, floristicamente, todos os trechos são similares, embora ocorram diferenças estruturais importantes entre eles.

Palavras-chave: floresta altomontana, Serra do Mar, florística e estrutura.

\begin{abstract}
The floristic and the structure of the Upper Montane Rain Forest, on five different mountains, along Serra do Mar, PR, were evaluated. Primary fragments, always above $1.250 \mathrm{~m}$ above sea level, were measured, with 10 rectangular samples $(5 \times 10 \mathrm{~m})(\mathrm{GBH}>10 \mathrm{~cm})$ for each site. There were registered 55 species (36 gen., 24 fam.). Including other author's data, it was possible to reveal that Ilex microdonta is the most important species, followed by Drimys brasiliensis, Ocotea catharinensis, Blepharocalyx salicifo lius and Gordonia fruticosa. It was observed the high arborous density, with more than 4.490 trees per hectare, which configures a single stratum, and medium height of $4 \mathrm{~m}$. On cluster analysis the best results were obtained by using the Importance Value. The minor stand similarity was registered among the sites on "morro do Araçatuba" $(1.610 \mathrm{~m})$ and "morro do Vigia" $(1.280 \mathrm{~m})$, indicating that the altitude factor has a powerful influence on this aspect. Although the Jaccard's index for all the sites revealed that despite of the structure significant differences, in relation to the floristic all of these were considered similar.
\end{abstract}

Key words: upper montane forest, Serra do Mar, floristic and structure.

\section{INTRODUÇÃO}

Há uma concordância entre diversos autores, dentre eles Stadmüller (1987), Salgado-Laboriau (1996), Sarmiento (1987), Roderjan (1994) e Bruijnzeel (1998) de que, para a vegetação tropical úmida, o clima das montanhas influencia fortemente a florística e a estrutura das florestas ali existentes, constituindo um gradiente vegetacional em concordância com a distribuição vertical de temperatura e umidade.

Com a elevação da altitude, as árvores apresentam-se de menor porte, a estratificação torna-se simplificada, o tamanho das folhas diminui e aumenta a presença de epífitas avasculares, musgos e liquens (Walter, 1986; Doumenge et al. 1995). Por sua vez, os solos tornam-se mais úmidos, muitas vezes, saturados

1. Engenheiro Florestal, M.Sc., Professor Auxiliar do Centro de Ciências Agrárias e Ambientais, Pontifícia Universidade Católica do Paraná, CEP 80215-901, Curitiba (PR). koehler@rla01.pucpr.br

2. Engenheiro Florestal, Dr., Professor Adjunto do Departamento de Ciências Florestais, Setor de Ciências Agrárias, Universidade Federal do Paraná, CEP 80210-170, Curitiba (PR). fgalvao@ floresta.ufpr.br

3. Engenheiro Florestal, Dr., Professor Titular do Departamento de Ciências Florestais, Centro de Ciências Rurais, Universidade Federal de Santa Maria, CEP 97105-900, Santa Maria (RS). longhiso@ccr.ufsm.br

Recebido para publicação em 16/04/2002 e aceito em 15/08/2002. 
em água e com elevado teor de matéria orgânica (Stadmüller, 1987). Com a ascensão ocorre também a desaceleração da dinâmica da vegetação. Waide et al. (1998) concluíram que as florestas de altitude regeneram-se num ritmo mais lento que as dos pisos altitudinais inferiores, explicado, em parte, pela lentidão do processo de ciclagem de nutrientes, fato esse con firmado por outros autores (Portes, 2000).

Essas peculiaridades podem ser observadas no conjunto montanhoso da Serra do Mar paranaense, dentro do complexo vegetacional atlântico, genericamente acima dos 1.150 m s.n.m. (Maack, 1968; Klein, 1979). Essa formação típica aparece descrita sob diversas denomina ções como "Mata de Neblina" (Maack, 1968; Walter, 1986), "Mata ou Floresta Nebular" (Bigarella, 1978; Falkenberg e Voltolini, 1995) e Floresta Ombrófila Densa Altomontana (Veloso e Goés-Filho, 1992), termo adotado neste trabalho.

A manutenção da integridade desses ambientes é fundamental, pois, entre outras funções, cumpre o papel importante na regulação do fornecimento de água em decorrência da capacidade de interceptação da umidade das nuvens (Hamilton et al., 1995), atua na estabilização dos solos íngremes das encostas elevadas (Bigarella, 1978), além do alto grau de endemismo assinalado para essas formações (Lewis, 1971; Sugden, 1982; Falkenberg e Voltolini, 1995; PARANÁ, 1995).

Considerando a carência de informações e a importância regional desses ambientes, o presente trabalho foi concebido com o objetivo de determinar padrões florísticos e estruturais da Floresta Ombrófila Densa Altomontana mediante comparação de levantamentos fitossociológicos efetuados em diferentes trechos primários da Serra do Mar, no estado do Paraná.

\section{MATERIAL E MÉTODOS}

\section{Localização e caracterização da área de estudos}

Todos os trechos incluídos neste trabalho inserem-se na porção paranaense da escarpa da Serra do Mar que, segundo Bigarella (1978), constitui a zona limítrofe entre o planalto e a planície litorânea.

Quatro trechos foram amostrados entre os anos de 1998 e 2000, e os resultados foram analisados em conjunto com os divulgados por Roderjan (1994) e Portes et al. (2001), ambos no morro Anhangava, e por Rocha (1999), entre os cumes do Gigante e da Ponta do Tigre, no conjunto montanhoso do Marumbi (Figura 1 e Tabela 1).
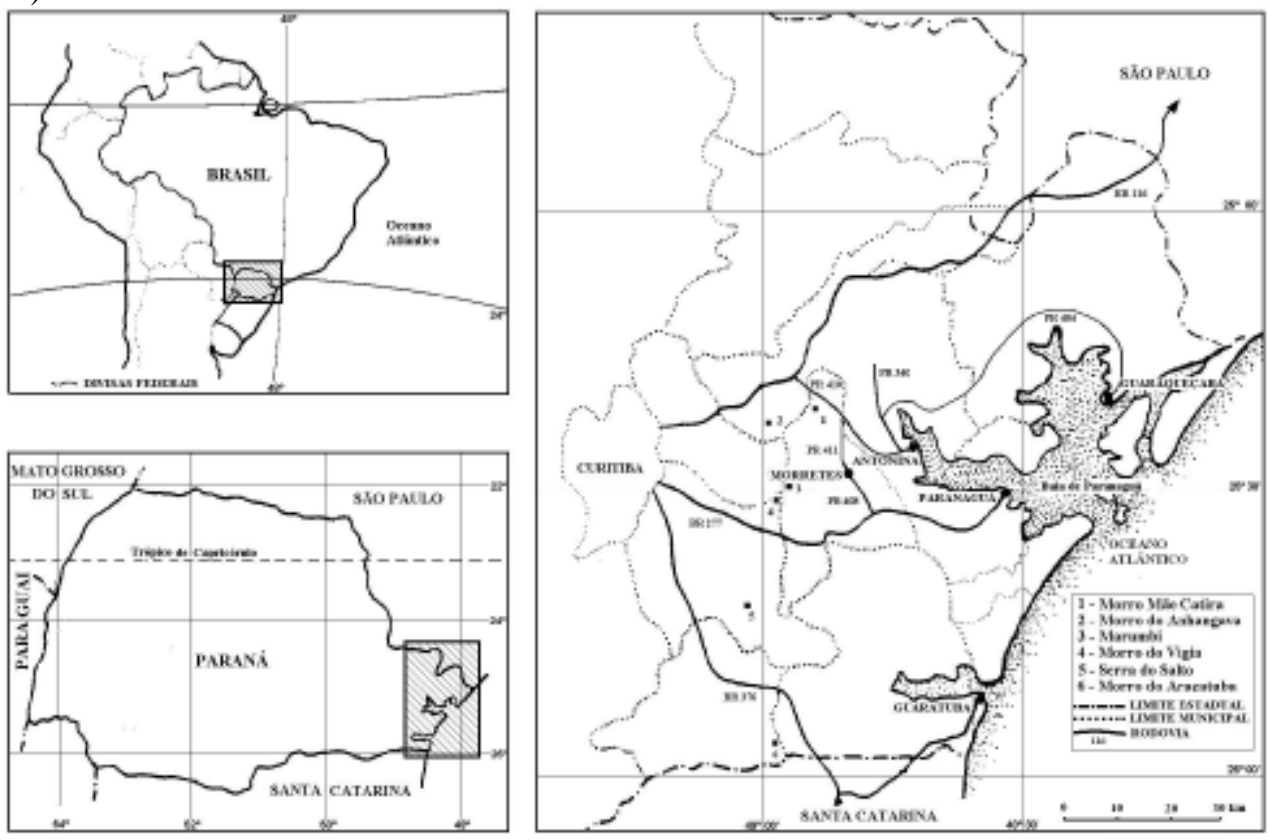

FIGURA1: Localização dos trechos da Floresta Ombrófila Densa Altomontana amostrados.

FIGURE 1: Localization of the Dense Upper Mountain Rain Forest sampled. 
TABELA 1: Localização geográfica das montanhas incluídas no presente estudo.

TABLE 1: Geographical position of the mountains included in this study.

\begin{tabular}{l|c|c|c|c}
\hline \multirow{2}{*}{ Topônimo } & \multicolumn{2}{|c|}{ Ponto Culminante $^{1}$} & \multirow{2}{*}{$\begin{array}{c}\text { Continentalidade } \\
(\mathrm{km})\end{array}$} \\
\cline { 2 - 4 } & Latitude & Longitude & $\begin{array}{c}\text { Altitude } \\
\text { (m. s.n.m.) }\end{array}$ & 78 \\
\hline Morro Mãe Catira & $2521^{\prime} 40,8^{\prime \prime}$ & $48^{\circ} 54^{\prime} 54,0^{\prime \prime}$ & 1.590 & 82 \\
Morro Anhangava & $25^{\circ} 23^{\prime} 54,0^{\prime \prime}$ & $48^{\circ} 59^{\prime} 43,2^{\prime \prime}$ & 1.460 & 67 \\
Marumbi & $25^{\circ} 29^{\prime} 10,8^{\prime \prime}$ & $48^{\circ} 57^{\prime} 27,0^{\prime \prime}$ & 1.380 & 70 \\
Morro do Vigia & $25^{\circ} 32^{\prime} 16,8^{\prime \prime}$ & $48^{\circ} 56^{\prime} 28,8^{\prime \prime}$ & 1.545 & 57 \\
Serra do Salto & $25^{\circ} 41^{\prime} 43,2^{\prime \prime}$ & $4902^{\prime} 39,0^{\prime \prime}$ & 1.390 & 43 \\
Morro Araçatuba & $25^{\circ} 54^{\prime} 07,8^{\prime \prime}$ & $48^{\circ} 56^{\prime} 02,0^{\prime \prime}$ & 1.610 & \\
\hline
\end{tabular}

Em que: ${ }^{1}$ Determinação feita com auxílio de GPS Garmin III Plus.

Nas partes elevadas, acima dos 800-1.000 m s.n.m., o clima regional, Cfa da Serra do Mar, passa a ser do tipo $\mathrm{Cfb}$, em razão da diminuição da temperatura média do mês mais quente para menos que $22^{\circ} \mathrm{C}$. Nas partes altas da serra registra-se também um aumento muito significativo na velocidade dos ventos (Maack, 1968; Roderjan, 1994).

A escarpa da Serra do Mar constitui uma barreira natural para os ventos alíseos úmidos vindos do SE que, em razão dessa interceptação, condensam-se e formam uma cobertura nebular freqüente, tendo como precipitação total valores superiores a $3.000 \mathrm{~mm}$ anuais para as encostas elevadas e os cumes (Roderjan, 1994; Rocha, 1999).

Em relação aos solos, predominam, sob a floresta altomontana, feições pouco desenvolvidas, sendo classificados genericamente como Neossolos Litólicos e Organossolos Fólicos, ambos rasos, com profundidade raramente superior a $50 \mathrm{~cm}$. São comuns também os Afloramentos de Rochas e, em locais menos íngremes, aparecem porções de Cambissolos (Roderjan, 1994).

\section{Procedimento metodológico}

Em todos os trechos seguiu-se uma metodologia-padrão que consistiu na delimitação de parcelas temporárias, em locais em que a floresta exibia a fisionomia característica de altomontana, ou seja, composta por árvores com troncos retorcidos, árvores baixas, presença em abundância de musgos nos ramos e nos galhos, respeitando-se a altitude mínima de 1.200 m s.n.m.

Em cada local, demarcou-se um número mínimo de dez parcelas de 5 x $10 \mathrm{~m}$, sendo estimadas as alturas e medidos os perímetros à altura do peito (PAP) de todos os espécimes cujos valores excediam a $10 \mathrm{~cm}$ de PAP. Todas as espécies amostradas foram coletadas e identificadas com ajuda de botânicos mediante comparação com exsicatas depositadas nos herbários do Museu Botânico Municipal (MBM), da Escola de Florestas da UFPR (EFC) e do Departamento de Botânica do Setor de Ciências Biológicas da UFPR (UPCB), todos esses em Curitiba.

Foram considerados para as análises dos dados atributos florísticos e estruturais como presença e ausência de espécies, densidade, dominância e valor de importância (Mueller-Dombois e Ellenberg, 1974). Para a análise de agrupamentos, adotou-se o método de ligação completa sendo a métrica a distância euclidiana quadrada para a geração de dendrogramas, gerados pelo software Statistica 5.

Para representação gráfica das famílias e das principais espécies em função dos parâmetros densidade e valor de importância respectivamente, foi utilizado o software AMADO 1.01.

\section{RESULTADOS E DISCUSSÃO}

\section{Composição florística}

Foram encontradas 24 famílias (Tabela 2, Figura 2), sendo Myrtaceae aquela que apresentou a maior diversidade no geral (7 gen., 16 spp.), seguida por Lauraceae ( 2 gen., 6 spp.) e Aquifoliaceae (1 gen., 4 spp.). Em termos numéricos, além das três famílias já citadas, Winteraceae e Theaceae também se destacam, 
embora representadas por apenas uma espécie cada que ocorrem em todos os trechos amostrados.

Winteraceae (1 sp.) em posição de destaque revela a influência de elementos, segundo Veloso e Goés-Filho (1992), de origem australásicos, mas, no geral, constatou-se uma maior representatividade e diversidade de grupos florísticos de distribuição universal.

TABELA 2: Lista de espécies encontradas nos diferentes trechos inclu ídos neste estudo.

TABLE 2: List of species registered on each fragment included in this study.

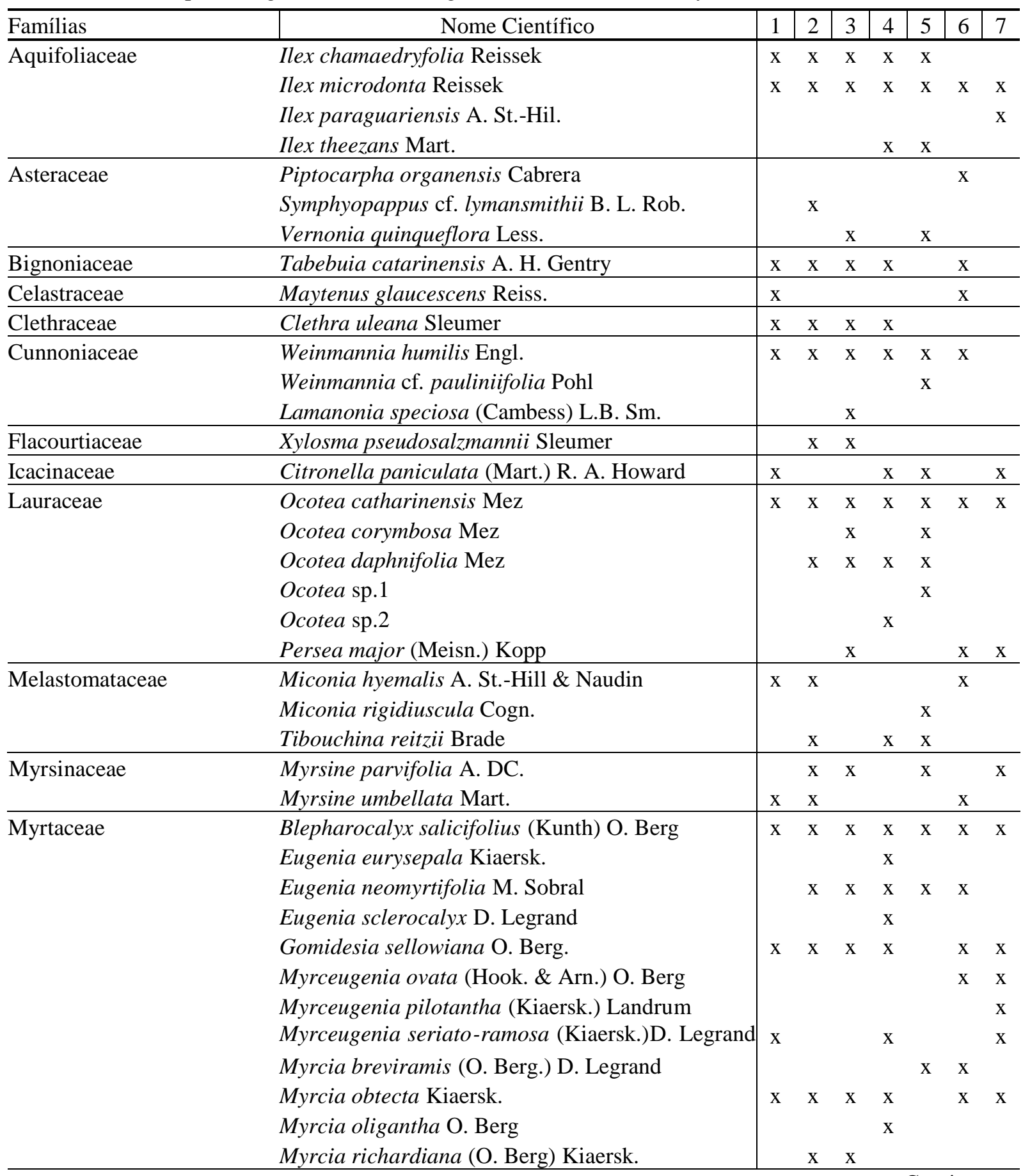

Continua $\ldots$ 
TABELA 2: Continuação ...

TABLE 2: Continued ...

\begin{tabular}{|c|c|c|c|c|c|c|c|c|}
\hline Famílias & Nome Científico & 1 & 2 & 3 & 4 & 5 & 6 & 7 \\
\hline Myrtaceae & $\begin{array}{l}\text { Myrcia sp. } \\
\text { Pimenta pseudocaryophyllus (Gomes) Landrum } \\
\text { Psidium spathulatum Mattos } \\
\text { Siphoneugena reitzii Legrand }\end{array}$ & $\mathrm{x}$ & $\mathrm{x}$ & $\mathrm{x}$ & $\mathrm{x}$ & $\begin{array}{l}\mathrm{x} \\
\mathrm{x}\end{array}$ & $\mathrm{x}$ & \\
\hline Ochnaceae & Ouratea vaccinioides Engl. & & & & $\mathrm{x}$ & & & \\
\hline Podocarpaceae & Podocarpus sellowii Klotzsch ex Eichler & & $\mathrm{x}$ & $\mathrm{x}$ & $\mathrm{x}$ & $\mathrm{x}$ & $\mathrm{x}$ & \\
\hline Polygonaceae & Coccoloba grandiflora Lindau & & & & & $\mathrm{x}$ & & \\
\hline Proteaceae & Roupala consimillis Mez ex Taub. & $\mathrm{x}$ & & & $\mathrm{x}$ & & & \\
\hline Rhamnaceae & Rhamnus sphaerosperma $\mathrm{Sw}$. & & $\mathrm{x}$ & $\mathrm{x}$ & & & & \\
\hline Rosaceae & Prunus cf. brasiliensis (Cham. \& Schltdl.) Dietrich & & & & & & & $\mathrm{x}$ \\
\hline Rubiaceae & Faramea multiflora A. Rich. ex DC. & & & & & $\mathrm{x}$ & & \\
\hline Sapotaceae & Crysophyllum sp. & & & & & $\mathrm{x}$ & & \\
\hline Styracaceae & Styrax martii Seub. & & & & & $\mathrm{x}$ & & \\
\hline Symplocaceae & $\begin{array}{l}\text { Symplocos aff. lanceolata (Mart.) A. DC. } \\
\text { Symplocos cf. paranaensis Bidá }\end{array}$ & $\mathrm{x}$ & $\mathrm{x}$ & & $\begin{array}{l}\mathrm{x} \\
\mathrm{x}\end{array}$ & $\mathrm{x}$ & $\mathrm{x}$ & $\begin{array}{l}\mathrm{x} \\
\mathrm{x}\end{array}$ \\
\hline Theaceae & Gordonia fruticosa (Schrad.) H. Keng & $\mathrm{x}$ & $\mathrm{x}$ & $\mathrm{x}$ & $\mathrm{x}$ & $\mathrm{x}$ & $\mathrm{x}$ & $\mathrm{x}$ \\
\hline Winteraceae & Drimys brasiliensis Miers & $\mathrm{x}$ & $\mathrm{x}$ & $\mathrm{x}$ & $\mathrm{x}$ & $\mathrm{x}$ & $\mathrm{x}$ & $\mathrm{x}$ \\
\hline Total (55 spp.) & ( s & 19 & 24 & 24 & 29 & 28 & 20 & 17 \\
\hline
\end{tabular}

Em que: 1 = Morro Mãe Catira; 2 = Morro Anhangava 1 (Roderjan, 1994); 3 = Morro Anhangava 2 (Portes et al., 2001); 4 = Marumbi (Rocha, 1999); 5 = Morro do Vigia; 6 = Serra do Salto; 7 = Morro Araçatuba.

Comuns, embora estejam ausentes em algumas áreas, são Cunoniaceae ( $3 \mathrm{spp}$.), Myrsinaceae (2 spp.) e Symplocaceae ( $2 \mathrm{spp}$ ), famílias as quais pertencem muitas espécies com comportamento pioneiro em pisos altitudinais inferiores.

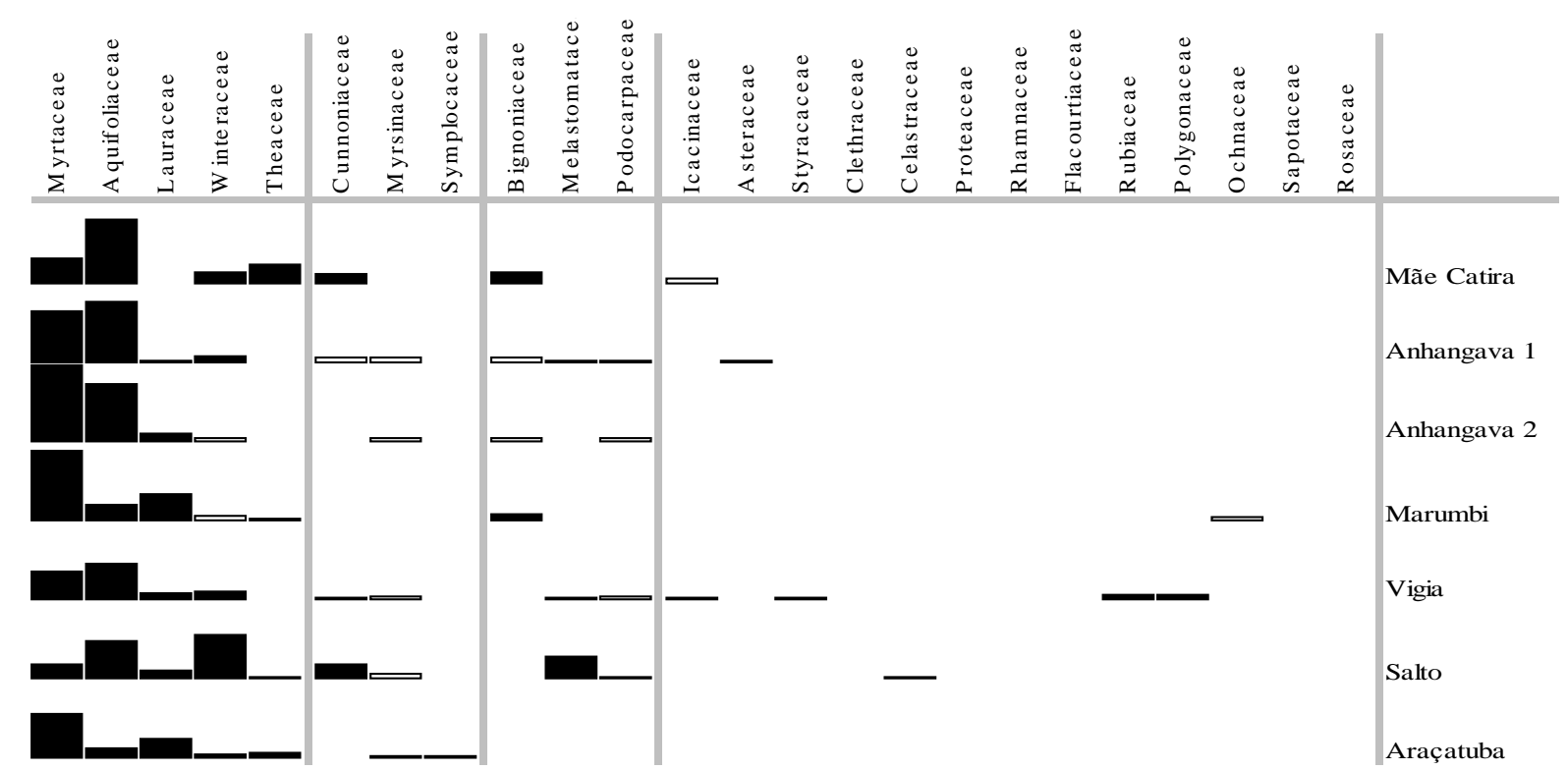

FIGURA 2: Ordenamento das famílias em função do parâmetro densidade relativa (em preto valores acima da média no trecho amostrado).

FIGURE 2: Families ordination for the relative density parameter (in black values greater than the mean in the sampled point). 
Com base nos dados, é possível inferir que o número de espécies nos pisos altomontanos é menor que nos de patamares inferiores, sobretudo no componente arbóreo. Nas seis diferentes montanhas incluídas no presente trabalho, foram registradas, em média, 23 espécies, tendo no geral 55 espécies pertencentes a 24 famílias (Tabela 2).

Em pesquisas fitossociológicas realizadas em trechos de menor altitude, pertencentes à Floresta Ombrófila Densa (Guapyassú, 1994), à Floresta Estacional Decidual (Longhi 1987, Longhi et al. 1999) e à Floresta Ombrófila Mista (Longhi, 1980; Jarenkow, 1985; Galvão et al., 1989; Koehler et al.,1998), foram registradas um número muito maior de espécies bem como de famílias mesmo em ambientes considerados perturbados.

Webster (1993) citou alguns gêneros como diagnósticos das florestas nebulares neotropicais e alguns coincidem com os registrados neste trabalho como Ilex, Drymis, Podocarpus, Miconia e Clethra.

Em relação aos índices de Jaccard (Tabela 3), é possível afirmar que não existem diferenças significativas entre os trechos estudados, pois o valor mínimo encontrado $(21 \%)$ está próximo ao sugerido por Mueller-Dombois e Ellenberg (1974) como indicador de similaridade cujo valor varia de 25 a 50\%.

TABELA 3: Similaridades florísticas com base em Jaccard (\%) para os trechos florestais altomontanos incluídos no estudo.

TABLE 3: Floristic Jaccard similarities for different fragments included on this study.

\begin{tabular}{|c|c|c|c|c|c|c|c|}
\hline & Mãe Catira & & & & & & \\
\hline Mãe Catira & - & $\begin{array}{c}\text { Anhangava } \\
1\end{array}$ & & & & & \\
\hline Anhangava 1 & 37 & - & \begin{tabular}{|c} 
Anhangava \\
2 \\
\end{tabular} & & & & \\
\hline Anhangava 2 & 34 & 63 & - & Marumbi & & & \\
\hline Marumbi & 45 & 46 & 43 & - & Vigia & & \\
\hline Vigia & 24 & 29 & 40 & 39 & - & Salto & \\
\hline Salto & 43 & 43 & 40 & 38 & 29 & - & Araçatuba \\
\hline Araçatuba & 37 & 30 & 26 & 30 & 21 & 39 & \\
\hline
\end{tabular}

O maior índice de similaridade de Jaccard foi registrado para os dois trechos localizados no morro Anhangava, o que parece ser bastante lógico por situarem-se na mesma montanha, diferindo apenas na orientação da encosta e, possivelmente, em nuances de profundidade e da estrutura dos solos. Da mesma forma, foi alta a similaridade entre os trechos do morro do Vigia e o do Marumbi, ambos inseridos na mesma subserra, mas discrepantes em rela ção à altitude e exposição.

A menor similaridade florística foi registrada entre os trechos dos morros do Vigia e do Ara çatuba (21\%), sendo esses os morros de maior e de menor altitudes e geograficamente afastados, quanto à latitude, em mais de $50 \mathrm{~km}$.

\section{Estrutura}

Em relação ao quociente de mistura de Jentsch - QM, que expressa a relação entre o número de espécies e o número de indivíduos, temos que, em média, seriam necessários oito indivíduos para cada nova espécie encontrada (Tabela 4). No morro do Vigia (28 spp.), coincidentemente na menor altitude, isso ocorre com um pouco mais de cinco indivíduos indicando indiretamente, uma maior riqueza de espécies. No morro do Araçatuba (18 spp.), registrou-se o menor número de espécies, mas a mistura florística é relativamente alta em função da baixa densidade observada nesta comunidade.

Em quatro dos trechos considerados, o que se destaca é a elevada densidade de árvores, chegando a um valor estimado de mais de 4.000 por hectare, sendo o diâmetro médio relativamente reduzido $(8,4 \mathrm{~cm})$. No entanto, em ambientes extremos, de dinâmica lenta, as árvores nunca atingem grandes dimensões. Esse fato também pode ser observado freqüentemente em Formações Pioneiras de Influência Marinha (restingas costeiras) e em Formações Pioneiras de Influência Flúvio-lacustre (floresta ripária) (Roderjan et al., no 
prelo).

Weaver et al. (1986) indicaram uma variação em área basal de 38 a $65 \mathrm{~m}^{2} / \mathrm{ha}$ para as florestas altomontanas tropicais, mas em três das situações reportadas no presente trabalho o valor desse descrit or ficou abaixo dos $30 \mathrm{~m}^{2} / \mathrm{ha}$ (Tabela 4). Mesmo assim, ainda pode ser considerado relativamente alto, se comparado à floresta do patamar montano ou a qualquer outra forma ção florestal bem-conservada cujos valores raramente excedem $50 \mathrm{~m}^{2} / \mathrm{ha}$.

Adotando-se como referências o número acumulado de espécies e a porcentagem de importância (Tabela 5), têm-se casos em que apenas dez espécies representam mais de $90 \%$ da comunidade. Weaver et al. (1986), estudando as florestas altomontanas, em Porto Rico, concluíram que cinco spp. representam mais de $90 \%$ da comunidade. Esse padrão difere dos resultados de pesquisas fitossociológicas em formações estabelecidas em pisos altitudinais inferiores (Jarenkow, 1985; Koehler et al., 1998) ou mesmo naquelas com estrutura e florística mais simplificada, como as florestas ripárias (Van Den Berg, 1995).

TABELA 4: Quadro resumo dos parâmetros florísticos e estruturais dos diferentes trechos altomontanos da Serra do Mar paranaense.

TABLE 4: Resume table of the floristic and structure parameters on different fragments of Upper Mountain forests in Serra do Mar, Paraná.

\begin{tabular}{l|ccc|c|c|c|c|c}
\hline Local & $\begin{array}{c}\text { Árv./ha } \\
(\text { vivas })\end{array}$ & $\begin{array}{c}\text { Árv./ha } \\
(\mathrm{mortas})\end{array}$ & $\begin{array}{c}\text { Área Basal } \\
\mathrm{m}^{2} / \mathrm{ha}\end{array}$ & $\begin{array}{c}\text { H média } \\
(\mathrm{m})\end{array}$ & $\begin{array}{c}\text { DAP médio } \\
(\mathrm{cm})\end{array}$ & $\begin{array}{c}\text { Número } \\
\text { espécies }\end{array}$ & QM & $\begin{array}{c}\text { Altitude } \\
(\mathrm{m})\end{array}$ \\
\hline Mãe Catira & 4320 & 80 & 28,05 & 3,50 & 7,23 & 19 & $1: 11,6$ & 1.350 \\
Anhangava 1 & 4490 & 340 & 41,87 & 4,60 & 7,64 & 24 & $1: 10,1$ & 1.350 \\
Anhangava 2 & 4087 & 331 & 29,29 & 3,50 & 8,00 & 25 & $1: 08,8$ & 1.400 \\
Marumbi & 3912 & 100 & 35,24 & $5,26^{1}$ & 8,68 & 29 & $1: 06,9$ & 1.350 \\
Vigia & 3140 & - & 29,46 & 4,10 & 7,98 & 28 & $1: 05,6$ & 1.250 \\
Salto & 4480 & 240 & 27,63 & 3,40 & 7,29 & 21 & $1: 11,2$ & 1.350 \\
Araçatuba & 2540 & 80 & 34,67 & 3,90 & 11,90 & 18 & $1: 07,3$ & 1.450 \\
\hline Média & 3852,7 & 195,2 & 32,3 & 4,00 & 8,4 & 23,4 & $1: 08,2$ & 1.357 \\
CV \% & 19,30 & 63,60 & 16,10 & 17,00 & 19,40 & 18,30 & 27,96 & 3,81 \\
\hline
\end{tabular}

Em que: ${ }^{1}$ Comprimento da árvore, conforme ROCHA (1999).

No morro Mãe Catira e em um dos trechos do morro Anhangava 2, Ilex microdonta (Figura 3) perfaz $34,2 \%$ e $36,6 \%$ respectivamente, sendo essa espécie registrada entre as quatro mais importantes em todos os trechos considerados.

Já no morro Araçatuba, a espécie mais importante perfaz $22,8 \%$ de toda a comunidade e as três mais importantes, Myrcia obtecta, Ocotea catarinensis e Gomidesia sellowiana respectivamente, juntas somam menos que 50\% do percentual de importância. Ilex microdonta nessa comunidade ficou em quarto lugar, com o menor valor de importância em comparação com todos os outros trechos.

TABELA 5: Porcentagem de importância acumulada para a primeira, as quatro primeiras, as oito primeiras e as dez primeiras espécies em cada trecho.

TABLE 5: Accumulated importance percentage for first, fourth, eighth and tenth species on each fragment.

\begin{tabular}{cccccccccc}
\hline N. spp. & Mãe Catira & Anhangava 1 & Anhangava 2 & Marumbi & Vigia & Salto & Araçatuba \\
\hline 1 & 34,2 & 28,1 & 35,6 & 15,2 & 18,8 & 24,1 & 22,8 \\
4 & 63,8 & 62,3 & 61,1 & 44,3 & 42,1 & 62,7 & 58,1 \\
8 & 85,5 & 76,6 & 75,5 & 63,6 & 60,9 & 78,4 & 80,4 \\
10 & 90,5 & 81,5 & 80,5 & 70,9 & 68,1 & 82,8 & 85,8 \\
\hline
\end{tabular}

No morro do Araçatuba, foram registradas espécies típicas de patamares inferiores das principais tipologias florestais sulinas, como Ilex paraguariensis e Prunus brasiliensis. Deve-se mencionar que a comunidade em questão está relativamente mais protegida dos rigorismos ambientais, sobretudo dos fortes ventos, por estar inserida em um vale. Em encostas expostas, essas espécies não foram encontradas, mesmo em altitudes mais baixas. A inclusão de Myrceugenia seriato-ramosa entre as mais importantes foi também 
reportada para o Marumbi (Rocha, 1999), sendo, ambos os casos, ambientes com abund ância de afloramentos rochosos.

Para o trecho do morro do Vigia, além de Ilex microdonta, representando mais de $34 \%$ do componente arbóreo, destaca-se outra Aquifoliaceae, Ilex chamaedryfolia. Deve ser destacado que a ocorrência significativa de Myrcia breviramis e de Coccoloba grandiflora, à frente de espécies típicas das formações altomontanas, revela haver uma forte presença de espécies oriundas da comunidade montana.

O registro, nesse trecho, de algumas espécies facilmente observadas na Floresta Ombrófila Mista como Blepharocalyx salicifolius, Gomidesia sellowiana e Gordonia fruticosa, essa de comportamento pioneiro (Reis et al. 1995), podem indicar um avanço da ocorrência desses representantes até o patamar altomontano, embora possivelmente nas montanhas mais próximas ao litoral (menor continentalidade) essas espécies não se estabeleçam.

a

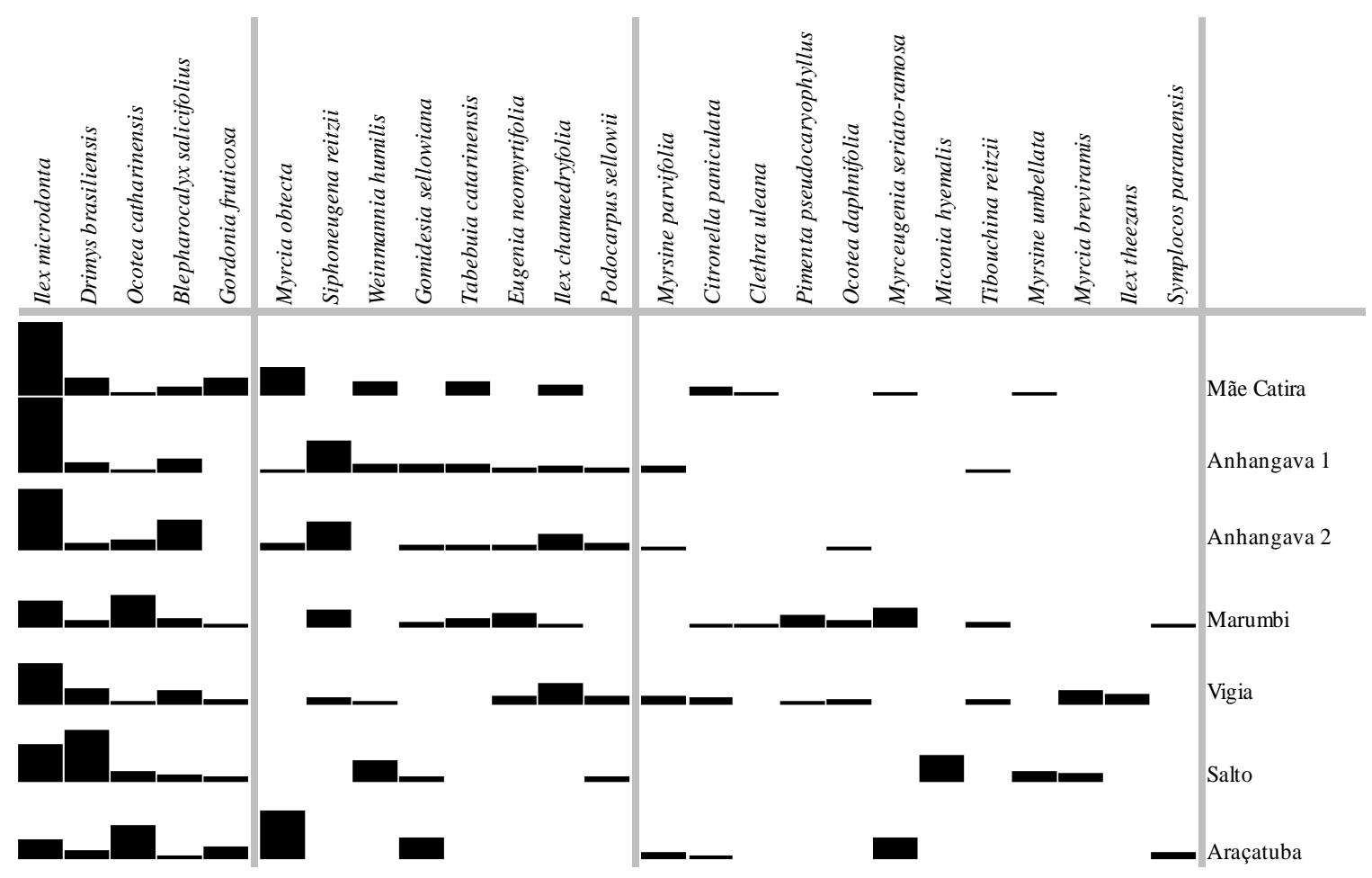

FIGURA 3: Ordenamento das principais espécies, com base no Valor de Importância dos trechos da Floresta Ombrófila Densa Altomontana incluídos, em que: a) grupo das espécies consideradas típicas; b) grupo de espécies comuns; c) grupo de espécies ocasionais (em preto, valores acima da média no trecho amostrado).

FIGURE 3: Ordination of the 26 main species, by the Importance Value and frequency on the seven fragments included on the Upper Montane Rain Forest. a) typical species; b) ordinary species; c) occasional species (in black, values greater than the mean in the sampled p oint).

Deve-se ainda citar algumas espécies com baixos valores de importância, mas com freqüência significativa, o que indica uma boa representatividade espacial nos trechos amostrados, sem que isso as coloque entre as espécies mais importantes no ambiente. Uma tipificadora dessa situação é Myrsine umbellata que aparece na comunidade com muitos indivíduos, mas com baixos diâmetros. Nos patamares 
altitudinais inferiores, essa espécie assume um caráter pioneiro e não é raro encontrar indivíduos com mais de $40 \mathrm{~cm}$ de diâmetro em florestas secundárias, quando partindo daí cedem espaço para espécies mais longevas.

\section{Análise de agrupamentos (Cluster)}

O agrupamento formado com base na combinação de variáveis mesológicas contínuas e estruturais produziu resultados interessantes (Figura 4 a). Basicamente dois grupos são marcadamente diferentes entre si. Os trechos dos morros Araçatuba e do Vigia formaram um grupo único, sobretudo por causa da variável densidade, com apenas 2.540 e 3.140 árv./ha respectivamente. Nos cinco demais trechos, em outro grupo, a densidade mínima é de 4.012 árv./ha, para um PAP mínimo de $10 \mathrm{~cm}$.
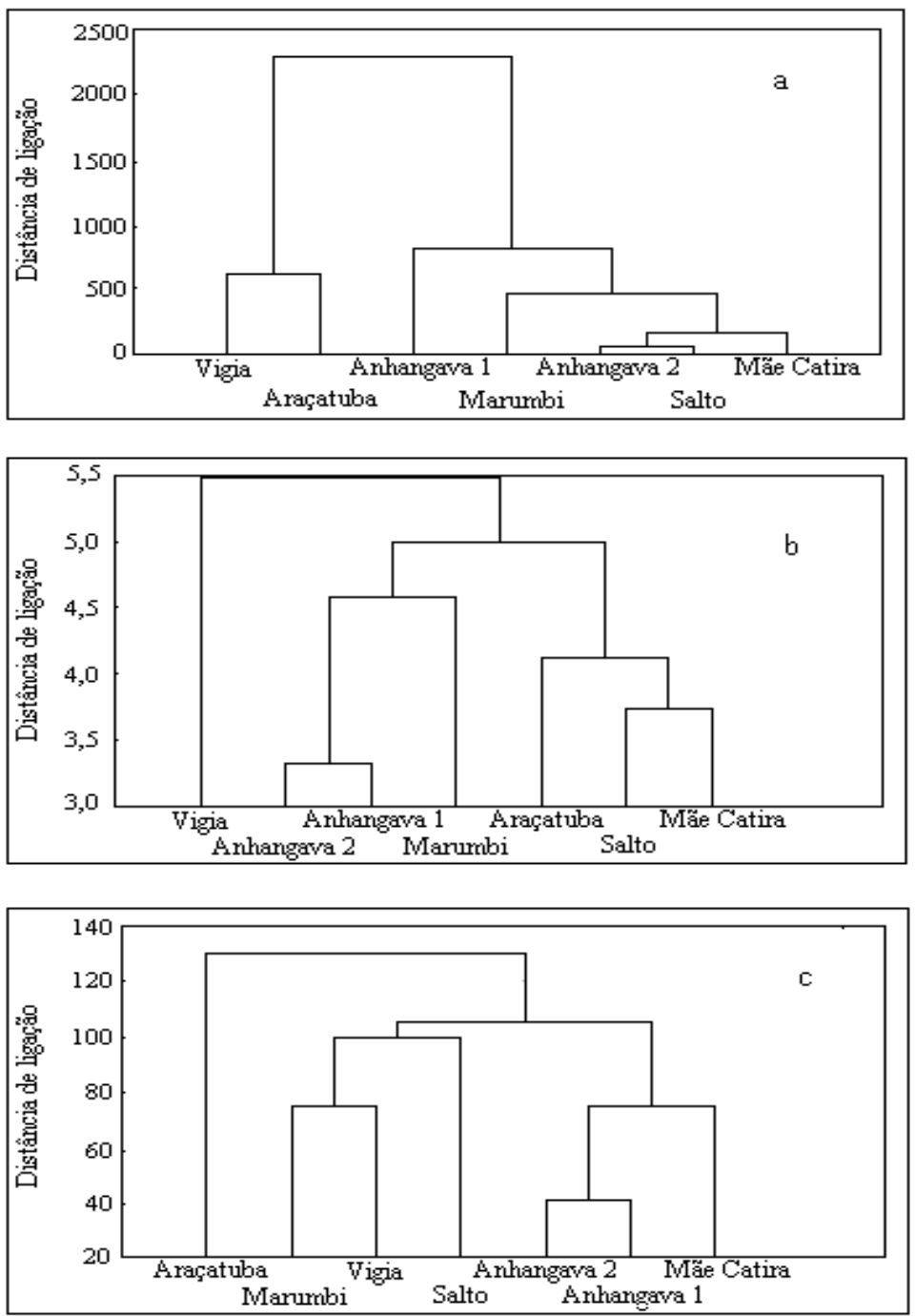

FIGURA 4: Dendrogramas formados com base em variáveis mesológicas, florísticas e estruturais, sendo: a) em função de número de espécies, número de famílias, densidade (árv./ha), dominância $\left(\mathrm{m}^{2} / \mathrm{ha}\right)$, altura média $(\mathrm{m})$, diâmetro médio $(\mathrm{cm})$, quociente de mistura, altitude (m s.n.m.) e distância em relação ao mar (km); b) em função da presença e ausência de espécies; c) em função do valor de importância.

FIGURE 4: Tree clustering from mesological, floristical and structural variables, where: a) number of species, number of families, $\mathrm{n} / \mathrm{ha}, \mathrm{m}^{2} / \mathrm{ha}$, average height $(\mathrm{m})$, average $\mathrm{DBH}(\mathrm{cm})$, mixture quotient, altitude and distance from the sea $(\mathrm{km})$; b) species presence/absence; c) value of importance. 
De fato, os dois trechos diferem dos demais, sendo o do morro do Vigia o mais pr óximo do ambiente de transição com a floresta montana, a 1.200 m s.n.m., e o trecho do Araçatuba inserido em um vale com muitos afloramentos de rocha e grotas. Essas condições, sem dúvida, determinam uma diminuição da densidade arbórea.

Isso indica que a variável densidade pode ser muito útil como critério de delimitação de patamares altitudinais da vegetação e que a floresta altomontana propriamente dita deve apresentar valores próximos ou superiores a 4.000 árv/ha, para um PAP igual ou superior a $10 \mathrm{~cm}$.

Os dois trechos do morro Anhangava foram colocados em grupos separados, não obstante sejam situados na mesma montanha, mas em faces diferentes. Essa separação ocorreu, sobretudo, pela grande diferença entre os trechos quanto às variáveis densidade e dominância. Uma possível explicação pode ser o fato de estarem em faces distintas e, nesse caso, a exposição parece exercer alguma influência na estrutura da floresta, corroborando as constatações de Dupuy et al.1993.

Por sua vez, o agrupamento baseado na presença e ausência de espécies (Figura 4 b) separou o morro do Vigia dos demais e colocou os dois trechos do morro Anhangava em um grupo único. A similaridade florística entre esses trechos é grande $\left(\mathrm{I}_{\mathrm{j}}=63,3 \%\right)$, como era de se esperar, pois estão inseridos na mesma montanha.

O dendrograma, obtido com base nos valores de importância, foi considerado o que melhor representa a situação (Figura 4 c). O primeiro grupo formado só pelo trecho do morro Araçatuba ilustra que o relevo pode influenciar a conformação estrutural da comunidade, pois, somente nesse caso, Ilex microdonta não aparece entre as quatro mais importantes

O grupo, que reúne os trechos do morro Anhangava e o do morro Mãe Catira, parece ser bastante adequado, pois a semelhança fisionômica é bastante pronunciada. Por tal, pode-se afirmar que o valor de importância é um bom parâmetro quando se deseja agrupar comunidades da mesma forma ção fitogeográfica, mas, espacialmente afastadas, pois ao que tudo indica assume a condição de uma variável bastante objetiva para sumarizar as informações estruturais.

\section{Diâmetros e alturas das árvores}

Quanto à distribuição diamétrica, constatou-se o predomínio numérico de árvores mais finas (Figura 5). Isso indica que o equilíbrio destas formações parece estar garantido, pois as árvores mortas ou senis têm reposição garantida. Essa situação repetiu-se para as quatro espécies mais importantes no geral, Ilex microdonta, Gordonia fruticosa, Drimys brasiliensis e Ocotea catharinensis, indicando que devam permanecer dominando a comunidade, dado o padrão de distribuição de diâmetros.
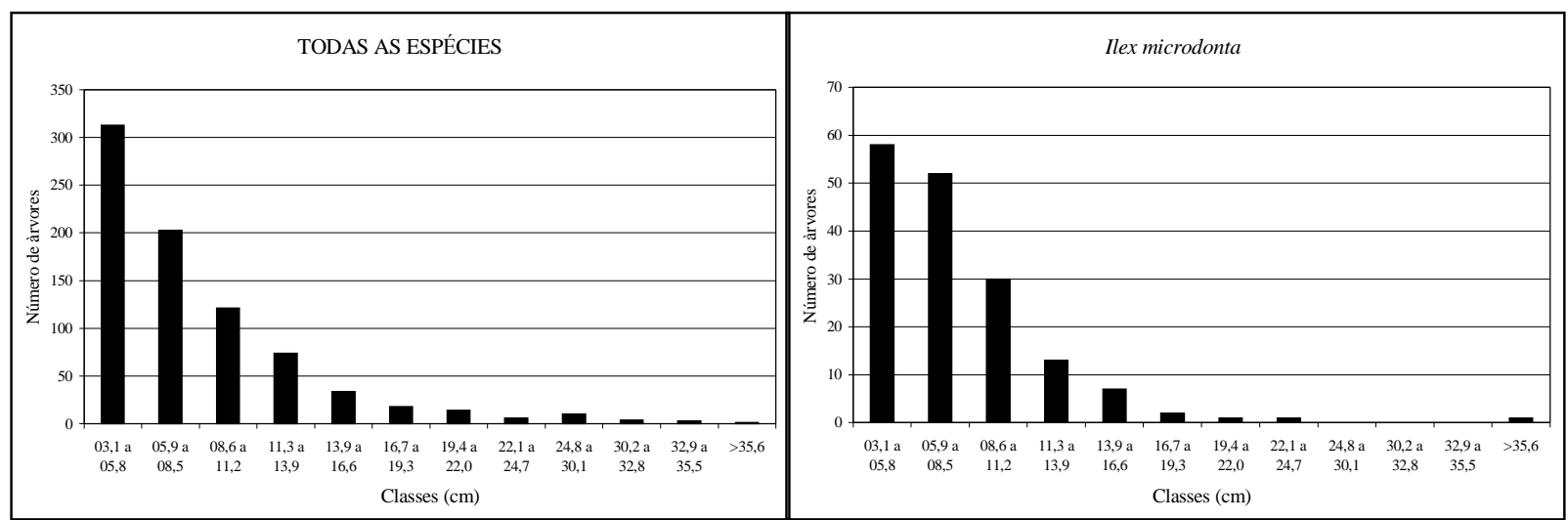

FIGURA 5: Freqüência das árvores por classes diamétricas para todas as espécies e para Ilex microdonta, considerando todos os trechos estudados.

FIGURE 5: Numeric frequency of the trees according to diametric classes, on all fragments included, for all species and for Ilex microdonta. 
Na literatura sobre as florestas altomontanas, é quase-unânime a constatação da estratificação única das comunidades, o que não ocorre nas florestas estabelecidas em menores altitudes, onde algumas árvores tendem a ocupar diferentes estratos, e em alguns casos com algumas espécies compondo um estrato emergente (Longhi, 1980; Jarenkow, 1985).

Essa configuração segue a lógica de que, em resposta aos rigorismos ambientais, sobretudo a incidência de fortes ventos e limitações do espaço disponível para sustentação radicial, a comunidade altomontana forma apenas um estrato. As alturas médias, variando em termos gerais entre 3 e $4 \mathrm{~m}$ (Figura 6), indicam que as árvores são muito menores que no patamar montano cuja altura média do estrato superior raramente fica abaixo de $10 \mathrm{~m}$ de altura, para muitas das espécies citadas.

Observou-se em campo que mesmo árvores com maior comprimento de tronco não são emergentes, inclinando-se de tal forma a não superarem o dossel único e compacto. Esse fato se observa sobretudo em árvores de maior diâmetro, levando a crer que a hipsometria, que representam, difere radicalmente das árvores estabelecidas nos pisos altitudinais mais baixos.

$\mathrm{O}$ fato de as árvores serem inclinadas parece estar relacionado com o movimento de massa d o solo morro abaixo, pela declividade do terreno, o que força as árvores a se inclinarem no sentido da vertente.

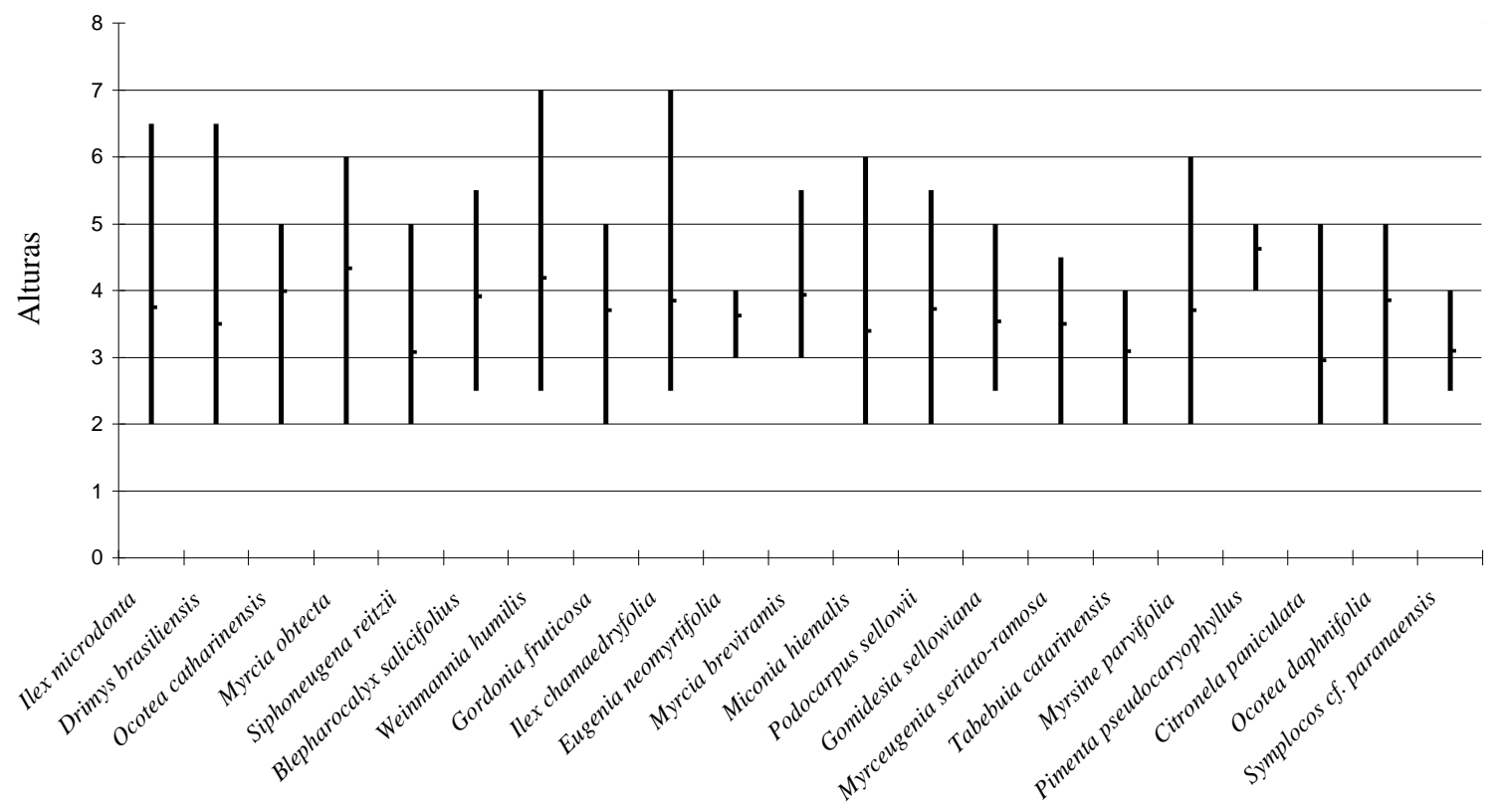

FIGURA 6: Alturas mínimas e máximas das principais espécies encontradas nos trechos de Floresta Ombrófila Densa Altomontana avaliados.

FIGURE 6: Vertical space occupied by trees, represented by the highest and lowest heights registered. The mark on the bar represents the average height for the species.

\section{CONCLUSÕES}

A análise conjunta de todos os trechos revela que peculiaridades do meio físico condicionam variações na florística e na estrutura da comunidade. Mesmo pequenos nuances dessas variações repercutem em mudanças perceptíveis na vegetação altomontana. Mas, em termos gerais, Ilex microdonta, enquanto numericamente soberana, tipifica a flores ta altomontana na Serra do Mar, no estado do Paraná.

Existem outras espécies sempre presentes nessa formação, mesmo que, em alguns casos, com baixo valor de importância. Como exemplos, pode-se citar Drimys brasiliensis, Ocotea catharinensis, 


\section{Blepharocalyx salicifolius e Gordonia fruticosa.}

O registro, em média, de apenas 23 espécies para todos os trechos florestais altomontanos considerados, reforça a hipótese de que condições ambientais adversas simplificam a florística de forma significativa.

A análise de agrupamentos (Cluster), baseada em parâmetros estruturais como densidade e dominância, diferenciou comunidades com alta similaridade florística. Por tal, parece lícito admitir que o sítio influencia marcadamente a estrutura, não obstante a presença e ausência de espécies permaneçam correlatas.

A análise de agrupamentos baseada no parâmetro valor de importância mostrou ser a opção mais eficiente para determinar similaridades entre diferentes comunidades inseridas em um mesmo contexto fisionômico-ecológico.

A baixa estatura das árvores e a ausência de árvores emergentes no estrato superior configuram um padrão fisionômico-estrutural inerente à Floresta Ombrófila Densa Altomontana.

\section{REFERÊNCIAS BIBLIOGRÁFICAS}

BIGARELla, J. J. (Coord.) A Serra do mar e a porção oriental do estado do Paraná: contribuição à geografia, geologia e ecologia regional. Curitiba: Paraná, 1978. 248p.

BRUIJNZEEL, L. A. Climatic conditions and tropical montane forest productivity: the fog has not lifted yet. (The Structure and Functioning of Montane Forests: Control by Climate, Soils, and Disturbance). Ecology, v. 79, n. 1, p. 10$15,1998$.

DOUMENGE, C.; GILMOR, D.; PEREZ, M. R.; BLOCKHUS, J. Tropical montane cloud forests: conservation staus and management issues. Ecological Studies, v. 110, p. 24-37, 1995.

DUPUY, J.M.; SANTAMARÍA, M.; CAVALIER, J. Estructura del bosque enano nublado de la Serrania de Macuira, en laderas de barlovento e sotavento. Biotropica, v. 25, n. 3, p. 340-343, 1993.

FALKENBERG, D. de B.; VOLTOLINI, J. C. The Montane cloud forest in southern Brazil. Ecological Studies, v. 110, p. 138-149, 1995.

GALVÃO, F; KUNIYOSHI, Y. S.; RODERJAN, C. V. Levantamento fitossociológico das principais associações arbóreas da Floresta Nacional de Irati-PR. Floresta, v. 19, n. 1/2, p. 30-49, 1989.

GUAPYASSÚ, M. dos S. Caracterização fitossociológica de três fases sucessionais de uma Floresta Ombrófila Densa Submontana, Morretes-Paraná. 1994. 165p. Dissertação (Mestrado em Engenharia Florestal) - Setor de Ciências Agrárias, Universidade Federal do Paraná, Curitiba.

HAMILTON, L. S.; JUVIK, J. O.; SCATENA, F. N. The Puerto Rico Tropical Cloud Forest Symposium: introduction and Workshop Synthesis. Ecological Studies, v. 110, p. 1-23, 1995.

JARENKOW, J. A. Composição florística e estrutura da mata com Araucária na estação ecológica de Aracuri, Esmeralda, Rio Grande do Sul. 1985. 85p. Dissertação (Mestrado em Ciências Biológicas) - Universidade Federal do Rio Grande do Sul, Porto Alegre.

KLEIN, R. M. Ecologia da flora e vegetação do Vale do Itajaí. Sellowia, n. 31, p. 1-389, 1979.

KOEHLER, A.; PÉLliCO NETTO, S.; SANQUETTA, C.R. Análise da estrutura de uma floresta Ombrófila Mista semidevastada, fazenda Gralha Azul, região metropolitana de Curitiba, com implicações ao manejo. Revista Acadêmica da PUCPR, n. 1, p. 37-60, 1998. Número dedicado à Agronomia.

LEWIS, W. H. High Floristic Endemism in Low Cloud Forests of Panamá. Biotropica, v. 3, n. 1, p. 78-80, 1971.

LONGHI, S. J. A estrutura de uma floresta natural de Araucaria angustifolia (Bert.) O. Ktze., no Sul do Brasil. 1980. 198p. Dissertação (Mestrado em Engenharia Florestal) - Setor de Ciências Agrárias, Universidade Federal do Paraná, Curitiba.

LONGHI, S. J. Aspectos fitossociológicos de uma floresta natural de Astronium balansae Engl., no Rio Grande do Sul. Rev. Centro de Ciências Rurais, Santa Maria, v. 17, n. 1/2, p. 49-61, 1987.

LONGHI, S. J; NASCIMENTO, A. R. T.; FLEIG, F. D.; DELLA-FLORA, J. B.; FREITAS, R. A.; CHARÃO, L. W. Composição florística e estrutura da comunidade arbórea de um fragmento florestal no município de Santa MariaBrasil. Ciência Florestal, v. 9, n. 1, p. 115-133, 1999. 
MAACK, R. Geografia física do Estado do Paraná. Curitiba: M. Roesner, 1968. 350 p.

MUELLER-DOMBOIS, D.; ELLENBERG, H. Aims and methods of vegetation ecology. New York: John Wiley \& Sons, 1974.

PARANÁ. Secretaria de Estado do Meio Ambiente. Lista vermelha das plantas ameaçadas de extinção no estado do Paraná. Curitiba, 1995. 139p.

PORTES, M. C. G. de O. Deposição de serapilheira e decomposição foliar em Floresta Ombrófila Densa Altomontana, Morro Anhangava, Serra da Baitaca, Quatro Barras-PR. 2000. 90p. Dissertação (Mestrado em Engenharia Florestal) - Setor de Ciências Agrárias, Universidade Federal do Paraná, Curitiba.

PORTES, M. C. G. de O.; GALVÃO, F.; KOEHLER, A. Caracterização florística e estrutural de uma Floresta Ombrófila Densa Altomontana do morro do Anhangava, Quatro Barras - PR. Floresta, v. 31, n. 1/2, 9-18, 2001.

REIS, A.; REIS, M. S.; QUEIROZ, M.H.; MANTOVANI, A.; ANJOS, A. dos. Caracterização de estágios sucessionais na vegetação catarinense. Florianópolis, 1995. p. 63-85. Apostila do curso ministrado para a Fundação de Meio Ambiente se Santa Catarina - FATMA, 1995.

ROCHA, M. do R. L. Caracterização fitossociológica e pedológica de uma Floresta Ombrófila Densa Altomontana no Parque Estadual Pico do Marumbi - Morretes, PR. 1999. 81p. Dissertação (Mestrado em Engenharia Florestal) - Setor de Ciências Agrárias, Universidade Federal do Paraná, Curitiba.

RODERJAN, C. V. A Floresta Ombrófila Densa Altomontana no Morro Anhangava, Quatro Barras, PR aspectos climáticos, pedológicos e fitossociológicos. 1994. 119p. Tese (Doutorado em Engenharia Florestal) Universidade Federal do Paraná, Curitiba.

RODERJAN, C. V.; GALVÃO, F.; KUNIYOSHI, Y. S.; HATSCHBACH, G. G. As unidades fitogeográficas do estado do Paraná, Brasil. Ciência \& Ambiente, n. 24. (no prelo)

SALGADO-LABORIAU, M. L. História ecológica da terra. São Paulo: Edgard Blücher, 1996. 307 p.

SARMIENTO, G. Los principales gradientes ecoclimáticos en los andes tropicales. In: CONGRESSO LATINOAMERICANO DE BOTÁNICA: ECOLOGIA DE TIERRAS ALTAS, 4., 1987, Bogotá. Anais... Bogotá. p. 47-64, 1987.

STADMÜller, I. Los bosques Nublados em el Trópico Húmedo. San José, Costa Rica: Universidad de las Naciones Unidas, 1987. 85p.

SUGDEN, A. M. The ecological, geographic, and taxonomic relationships of the flora of an isolated Colombian Cloud Forest, with some implications for island biogeography. Journal of the Arnold Arboretum, v. 63, p. 31-61, 1982.

VAN DER BERG, E. Estudo florístico e fitossociológico de uma floresta ripária em Itutinga, MG, e análise das correlações entre variáveis ambientais e a distribuição das espécies de porte arbóreo-arbustivo. 1995. 73p. Dissertação (Mestrado em Engenharia Florestal) - Universidade Federal de Lavras, Lavras.

VELOSO, H. P; GOES FILHO, L. Fitogeografia brasileira, classificação fisionômica ecológica da vegetação neotropical. Rio de Janeiro: IBGE, 1992.123p. (Boletim Técnico Projeto RADAMBRASIL).

WAIDE, R. B.; ZIMMERMAN, J. K.; SCATENA. F. N. Controls of primary productivity: lessons from the Luquillo Mountains in Puerto Rico. Ecology. v. 79, n. 1, p. 31-37, 1998.

WALTER, H. Vegetação e zonas climáticas: tratado de ecologia global. São Paulo: E.P.U., 1986. 327p.

WEAVER, P. L.; MEDINA, E.; POOL, D.; DUGGER, K.; GONZALES-LIBOY, J.; CUEVAS, E. Ecological Observations in the Dwarf Cloud Forets of the Luquillo Mountains in Puerto Rico. Biotropica, v. 8, n. 1, p. 79-85, 1986.

WEBSTER, G. L. The panorama of Neotropical Cloud Forests. In: CHRCHILL, S. P.; BALSLEY, H; FORERO, E.; LUTEYN, J. L. (Eds.). Biodiversity and conservation of netropical Montane Forests. The New York: Botanical Graden, 1995. p. 53-77. 